\title{
Spawning aggregations: patterns of movement of the coral trout Plectropomus leopardus (Serranidae) as determined by ultrasonic telemetry
}

\author{
Dirk C. Zeller* \\ Department of Marine Biology, James Cook University of North Queensland, Townsville, Queensland, 4811, Australia
}

\begin{abstract}
This study measured biological variables necessary for determining the dynamics of spawning aggregations and measured the influences of these variables on effects of fishing on these aggregations. Four major spawning aggregation sites of Plectropomus leopardus (Serranidae) were identified at Lizard Island, Northern Great Barrier Reef, Australia, using ultrasonic telemetry. Spawning aggregation activities displayed a lunar pattern, with peak activities during new moon periods in the austral spring-early summer. Of 35 fish tracked during spawning periods in 1993-95, only $31 \%$ participated in spawning aggregations, despite all specimens being sexually mature. All specimens that aggregated displayed fidelity to their chosen aggregation site. The distance between established home ranges and spawning aggregation sites ranged from 220 to $5210 \mathrm{~m}$, with total spawning movements back and forth for individual fish ranging from $600 \mathrm{~m}$ to over $17 \mathrm{~km}$. One-way inter-reefal movements were recorded for 3 fish moving $3,7.5$, and $11 \mathrm{~km}$ between release and recapture locations. Male fish spent an average of 8 times longer at aggregations than females. Females $(n=4)$ undertook single-day or overnight trips only, while males $(\mathrm{n}=8$ ) often did multi-day trips. Males were also more likely to make several trips to spawning aggregation sites than females. Since males spent more time at aggregation sites, and made more trips to those sites, they were potentially more vulnerable to fishing pressure on aggregations. The reliance on several aggregation sites per reef makes $P$. leopardus potentially less vulnerable to overexploitation of spawning aggregations. However, the strong site fidelity observed makes individual aggregations vulnerable to depletion. The low participation rate of reproductively mature individuals at major aggregation events $(31 \%)$ suggested that not all spawning activity took place at the known aggregation sites.
\end{abstract}

KEY WORDS: Spawning aggregations - Movements Plectropomus leopardus - Ultrasonic telemetry Catchment distance Serranidae - Residence Sex patterns - Fisheries management - Stock assessment

\section{INTRODUCTION}

A common reproductive strategy of coral reef fishes is to form spawning aggregations (Thresher 1984), either on a daily basis with associated movements over short distances (e.g. Colin \& Clavijo 1988, Myrberg et al. 1988, Mazeroll \& Montgomery 1995), or on a seasonal basis as a result of large-scale migrations (e.g Shapiro 1987, Colin 1992, Shapiro et al. 1993). Fish

•E-mail: dirk.zeller@jcu.edu.au stocks on coral reefs are being exposed to increasing pressures due to human population growth and economic development leading to rising fishing effort. Of particular concern are the fishing pressures on spawning aggregations, which are often fished heavily once the location is known to the fishing community (e.g. Johannes et al. 1994, 1995, Sadovy 1994, Sadovy \& Domeier 1994). Efficient fishing at aggregation sites can result in the removal of a large proportion of the reproductively active fish, which may have significant effects on the population as well as on future fishery yields (Shapiro 1987, Colin 1992, Johannes et al. 1994. Sadovy 1994). 
The effects of fishing pressure on spawning aggregations of a population of coral reef fish is strongly influenced by several factors. These factors include the number of distinct spawning aggregation sites, the catchment distances (i.e. How far do individuals move to specific aggregation sites?), the participation rates (What proportion of the population participates in any one aggregation event?), the residence times of individual fish at aggregation sites, and any potential differences between the sexes in the participation rates and residence times. Information regarding the catchment distances of spawning aggregations and distances moved by individual fish is limited. Most data on distances moved are based either on chance recapture of tagged specimens (Burnett-Herkes 1975 in Shapiro 1987, Colin 1992, Sadovy et al. 1994, Johannes et al. 1995), or qualitative observations (Colin et al. 1987, Colin 1992). There is no quantitative information about participation rates or residence duration of individuals at aggregation sites of large predatory reef fish. Any estimates of abundance and sex ratios at spawning aggregations will depend strongly on turnover rates of fish during the existence of an aggregation (Johannes et al. 1994). Clearly, the determination of catchment distances of spawning aggregations, and the participation rates and residence times at these aggregations, for a given species is important for fisheries management.

Spawning aggregations have been documented for many species through direct observations (e.g. Robertson 1983, Shapiro 1987, Colin 1992, Shapiro et al. 1993, Sadovy et al. 1994, Mazeroll \& Montgomery 1995, Warner 1995), or inferred from catch and reproductive information (Ebisawa 1990, Davis \& West 1993). Spawning aggregations of Plectropomus areolatus have been reported in Palau (Micronesia) (Johannes 1981) and the Solomon Islands (Johannes 1988). On the Great Barrier Reef (Australia), the first scientific investigation of spawning aggregations of the protogynous Plectropomus leopardus (coral trout) were reported by Samoilys \& Squire (1994) and Samoilys (1997), although anecdotal information was reported earlier (e.g. Johannes \& Squire 1988). This serranid forms the major component of the commercial and recreational hook and line catch on the Great Barrier Reef (Kailola et al. 1993, Williams \& Russ 1994, Higgs 1996).

The focus of this study can be divided broadly into 2 sections: (1) The location of spawning aggregation sites of Plectropomus leopardus on the study reef were determined through tracking of individuals equipped with ultrasonic telemetry transmitters. Once aggregation sites had been identified, the catchment distances of aggregations were estimated by measuring the distances moved between established home ranges (Zeller 1997a, b) and aggregation sites using ultrasonic tracking. (2) The use of spawning aggregations by $P$. leopardus was examined by comparing the underwater visual censuses of spawning aggregations with the behaviour of tracked individuals. Ultrasonic tracking permitted the quantification of participation rates of $P$. leopardus at aggregation events and determined the timing of movements to and from spawning aggregation sites. The residence time and number of spawning trips undertaken by individual $P$. leopardus was determined, and any sex-specific differences in the patterns of use of aggregation sites were evaluated.

\section{MATERIALS AND METHODS}

This study was conducted at Lizard Island, northern Great Barrier Reef (GBR), Australia (lat. $14^{\circ} 40^{\prime} \mathrm{S}$, long. $145^{\circ} 28^{\prime} \mathrm{E}$ ) between January 1993 and December 1995. Lizard Island is a high, continental island, situated in the GBR lagoon. It is surrounded by fringing reefs, which enclose a local reef lagoon and 2 nearby, small islands (Palfrey and South Islands) (Fig. 1). Waters around the island are relatively shallow (20 to $30 \mathrm{~m}$ ). The majority of this study was conducted on the north, north-east and west sides of the island, these areas being more sheltered from the prevailing south-east winds.

Emphasis was placed on spreading the capture and release locations of specimens across the whole study area in order to increase the likelihood of detecting spawning aggregation sites and to determine the catchment distances of each aggregation site. Three extensive ultrasonic tracking periods took place during the spring-early summer period in the southern hemisphere, between August and December 1993, 1994 and 1995, which is the reported spawning period for Plectropomus leopardus on the northern GBR (Samoilys \& Squire 1994, Ferreira 1995).

Ultrasonic tracking. Individuals of Plectropomus leopardus used for ultrasonic tracking were captured on hook and line. Ultrasonic transmitters (Vemco Ltd and Sonotronics Ltd) were surgically implanted into the body cavity of specimens anaesthetised with MS222 (tricaine methanesulfonate) (Hart \& Summerfelt 1975, Mortensen 1990, Holland et al. 1993, Zeller 1997 aj. Fish were released at the capture sites after an aquarium based recovery period of 2 to $3 \mathrm{wk}$ (Zeller 1997a). Tracking of specimens commenced immediately after release, but data collected during the first $24 \mathrm{~h}$ after release were not included in any subsequent analyses. A total of $35 P$. leopardus were tracked during the 3 spawning periods monitored, with tracking periods up to $97 \mathrm{~d}$ per fish. Individual fish could be 


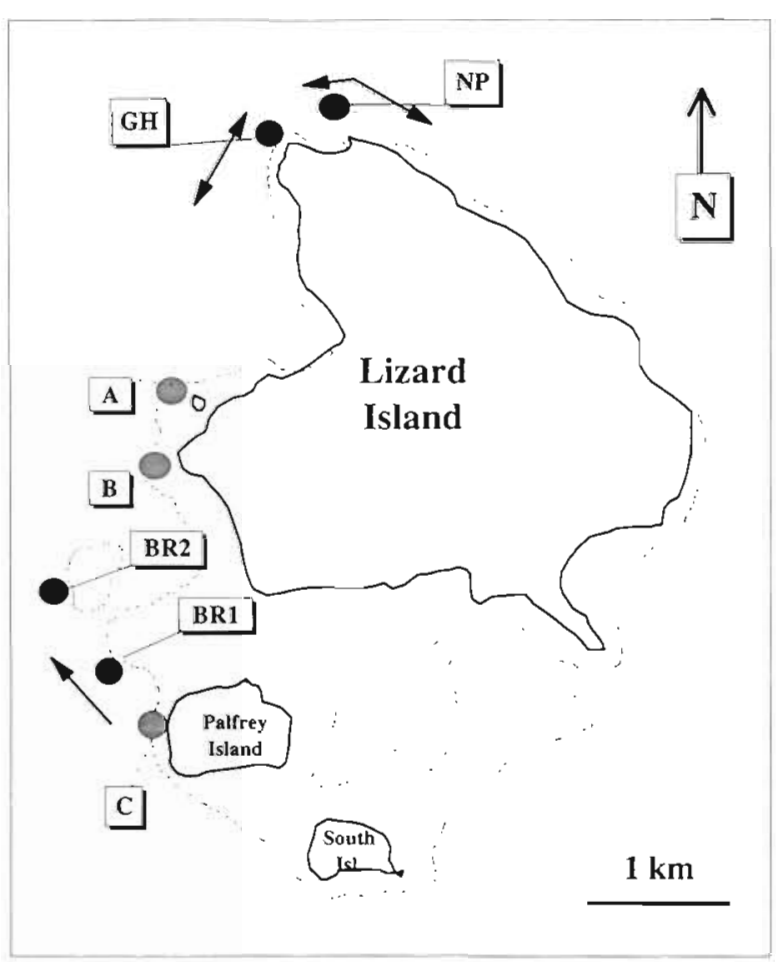

Fig. 1. Plectropomus leopardus. Locations of major spawning aggregations and minor courtship sites of coral trout at Lizard Island (northern Great Barrier Reef, Australia), as identified through ultrasonic telemetry and underwater visual surveys on Scuba between 1993 and 1995. Prevalent tidal currents are indicated (arrows). Prevailing winds from south-east. Stippled line indicates approximate reef-sand interface or $20 \mathrm{~m}$ depth contour (-) Major aggregation sites: NP. North Point, GH: Granite Head, BR1: Backreef Site 1, BR2: Backreef Site 2. (-) Minor courtship sites: A: Osprey Island, B: Corner Beach Reef, C: Palfrey Island

identified by the ultrasonic transmitter frequency and the different pulse rates on each frequency (pulses $\min ^{-1}$ ). The tracking technique followed the small vessel techniques described by Holland et al. (1985), Matthews et al. (1990) and Zeller (1997a). Each fish was located at least 3 to 4 times per day for the duration of the tracking period. Exact position fixing of fish equipped with ultrasonic transmitters was by visual triangulation (White \& Garrot 1990) using reef- and landfeatures identifiable on aerial photographs. Pilot investigations indicated that location of the signal could be determined to within approximately 10 to $20 \mathrm{~m}$ using crossbearings at approximately $90^{\circ}$ to each other (Zeller 1997a). At the end of each tracking period, individuals were collected by speargun to recover transmitters and determine the sex and reproductive status of individuals. Histological techniques used for reproductive assessment followed those described by Ferreira (1995) for P. leopardus.
Underwater visual census. Underwater visual censuses were conducted to confirm the existence of spawning aggregation sites determined by movements of tracked individuals. Censuses were spread across the complete lunar periods to estimate abundances of Plectropomus leopardus at spawning sites. After initial, widespread searches of each spawning site, a core area of 50 by $20 \mathrm{~m}$ was censused. During each $20 \mathrm{~min}$ census, these core areas were searched intensively and all sighted coral trout counted, their sizes estimated, male courtship colour and behaviour noted (sensu Samoilys \& Squire 1994), and tracked individuals identified where possible. Identification of tracked specimens was achieved by specimen-specific tagging patterns using standard T-bar anchor tags (1993), or by use of a diver held ultrasonic receiver (1994-95).

Data analysis. Data were examined graphically and analysed for diel and lunar patterns of spawning movements, residence times at spawning sites and distances moved to spawning sites. The spatial location data obtained from the ultrasonic tracking were digitised from aerial photos. Distances moved and speed of movements from home ranges to spawning aggregation sites were analysed using the home range analysis program Wildtrack ${ }^{0}$ (Todd 1993). To avoid overestimation of residence time and to ensure that the correct departure time from spawning sites was recorded, only those spawning site movements which included ultrasonic telemetry records of both evening and morning nautical twilight were considered in the analysis.

Statistical analyses included $t$-test, ANOVA, ANCOVA, linear regression, and $\chi^{2}$-test. Statistical assumptions, e.g. heteroscedasticity and non-normality and independence of errors, were examined prior to analysis (Underwood 1981). Data were transformed using the standard $\log _{10}$ transformation when required (Underwood 1981). Proportions were transformed to arcsine square-root for biostatistical evaluation; raw data was used for interpretation of observed patterns (Sokal \& Rohlf 1981, Underwood 1981).

\section{RESULTS}

Of the 35 individual Plectropomus leopardus (Forklength, $\mathrm{FL}$, range $=37.6$ to $67.5 \mathrm{~cm}$ ) tracked during the 3 spawning periods monitored, 13 (31.1\%) were recorded as moving to spawning aggregation sites $(\mathrm{FL}$ range $=43.9$ to $58.5 \mathrm{~cm}$ ). Eight individuals were male, 4 were female and 1 specimen could not be recovered for sex determination. The remaining specimens remained at their home range sites (Zeller $1997 \mathrm{~b}$ ). A total of 1698 tracking days and 6647 timelocation data points were obtained during the spawning periods. 


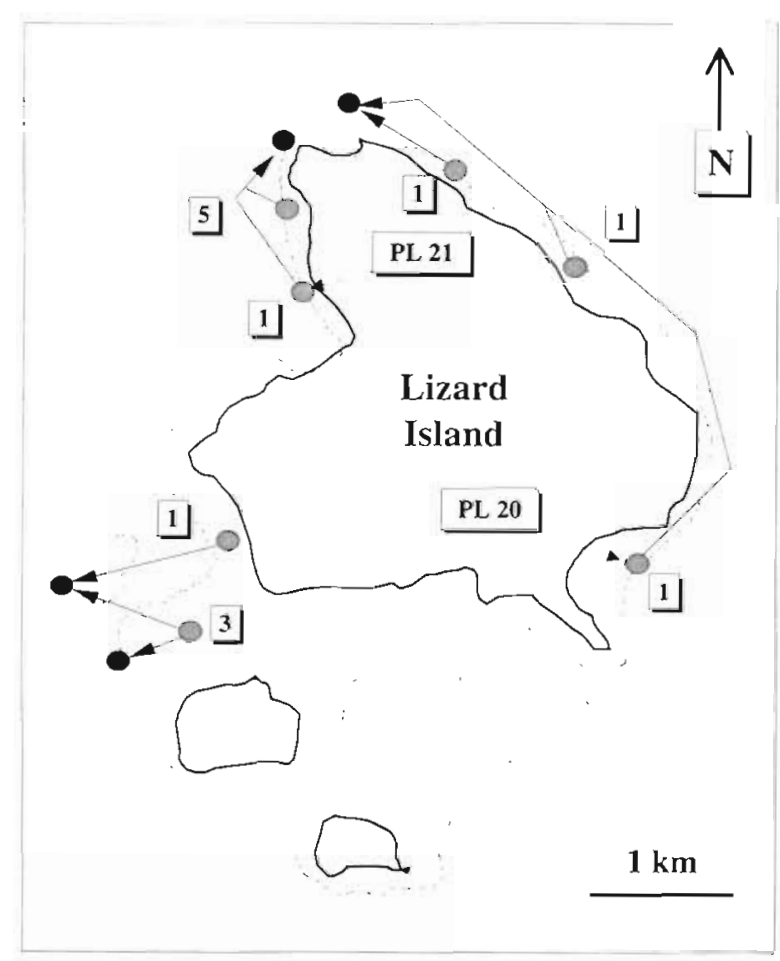

Fig. 2. Plectropomus leopardus. Locations of home ranges of the 13 coral trout tracked using ultrasonic telemetry between 1993 and 1995 which participated at aggregation events, and schematic movement paths to their respective spawning aggregation sites (arrows). Numbers indicate the number of tracked fish participating in aggregation events. PL 20 and PL 21 identify home range locations of 2 specific individuals. (O) Locations of home ranges; (O) spawning aggregation sites. Stippled line indicates approximate reef-sand interface or $20 \mathrm{~m}$ depth contour

\section{Spawning aggregation sites}

Around Lizard Island, 4 major aggregation sites (sensu Samoilys \& Roelofs 1996) of Plectropomus leopardus were detected through movements of fish equipped with ultrasonic transmitters. Two of the sites were identified in 1993 and confirmed in 1994 and 1995 (Granite Head and North Point, Fig. 1), while the 2 backreef sites (BR1 and BR2, Fig, 1) were located during 1995.

All aggregation sites were situated on the lower reef slope at a depth of 15 to $20 \mathrm{~m}$, which represented the deepest part of the reef slope at Granite Head and North Point. Both backreef aggregations (BR1 and BR2) continued to a depth of $25 \mathrm{~m}$, but visual observations and censuses were restricted to $20 \mathrm{~m}$. All 4 sites were located at the down-current position of the local reef structures, with medium to strong tidal currents being experienced regularly, running either off the reef or parallel to the reef edge (Fig. 1).
Courtship activities were observed during visual surveys at 3 additional locations during 1995 (A, B and C, Fig. 1). At these locations 1 or 2 male Plectropomus leopardus were observed displaying courtship behaviour (Samoilys \& Squire 1994) towards groups of between 2 and 6 other coral trout (presumably females)

\section{Catchment distances: distances moved to spawning sites}

The 1-way distances between established home ranges and spawning aggregation sites for Plectropomus leopardus equipped with transmitters varied widely, ranging from $220 \mathrm{~m}$ to a maximum of $5210 \mathrm{~m}$ [mean: $912 \mathrm{~m} \pm 233$ (SE), $\mathrm{n}=13$, Fig. 2]. Treating the individual 1 -way distances between home ranges and spawning sites as covariate for each specimen in the statistical analysis, the total distance moved to spawning aggregation sites (return trips and multiple trips) did not differ between male and female $P$. leopardus (ANCOVA $F_{[1,9]}=0.7869, p=0.3981$ ). Taking into account return trips and multiple movements (2 or more return trips) to aggregation sites, the distance moved ( $\pm \mathrm{SE}$ ) by coral trout in relation to spawning during the tracking periods averaged $5220 \mathrm{~m} \mathrm{(} \pm 1315)$ and ranged from 600 to $17270 \mathrm{~m}$. The maximum recorded distance of over $17 \mathrm{~km}$ was based on a male individual (PL 21) which undertook 10 separate trips between its home range and the spawning aggregation site at Granite Head, a distance of $860 \mathrm{~m}$ each trip, over a $19 \mathrm{~d}$ period during 1994 (PL 21, Fig. 2). Two of these trips were of multi-day duration $(2$ and $3 \mathrm{~d}$, respectively), and on 2 occasions this fish made 2 trips back and forth on the same day. The average speed ( $\pm \mathrm{SE}$ ) of movement to and from the aggregation site for $\mathrm{PL} 21$ was $11 \pm 1.5 \mathrm{~m} \mathrm{~min}^{-1}(\mathrm{n}=10)$. For all fish and all occasions with home range and spawning site fixes on the same day, the speed of movement $( \pm \mathrm{SE})$ in relation to aggregation sites averaged $10 \pm 1.2 \mathrm{~m} \mathrm{~min}^{-1}(\mathrm{n}=20)$, with a range of 3 to $20 \mathrm{~m} \mathrm{~min}^{-1}$

\section{Evidence of inter-reefal movements}

Three recaptures of coral trout carrying ultrasonic transmitters can be classified as inter-reefal movements. Furthermore, these movements represent long distance movements away from a known spawning aggregation site. One specimen $(F L=48.0 \mathrm{~cm})$ was captured initially in August 1993 (4 d post-new moon) at the Granite Head spawning aggregation site. Ultrasonic tracking contact in the Granite Head area was lost $7 \mathrm{~d}$ after release. The fish was recaptured by com- 


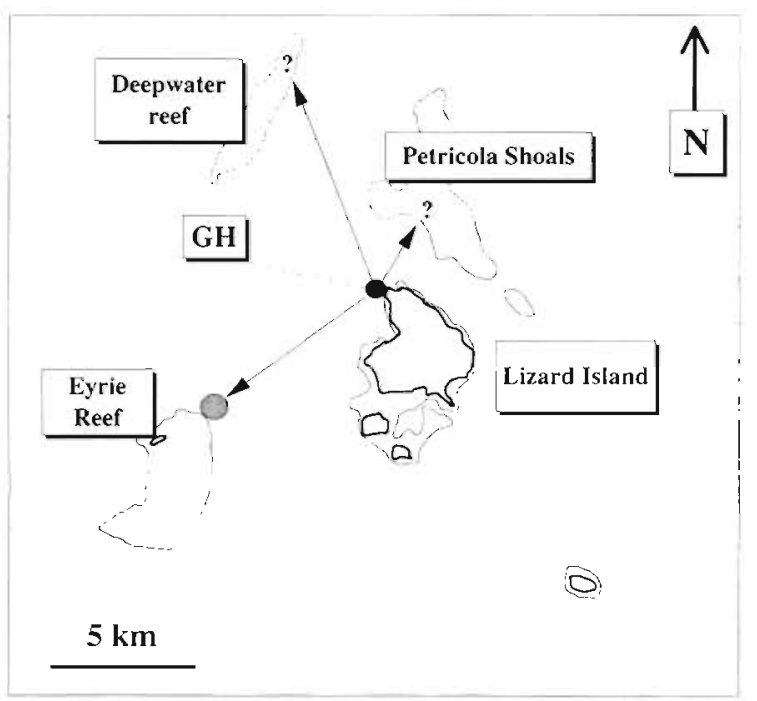

Fig. 3. Plectropomus leopardus. Initial capture and release location at Granite Head (GH) spawning aggregation site during new moon periods in 1993/1994 of 3 coral trout equipped with ultrasonic transmitters. Contact with spec1mens was lost shortly after release. Locations of recapture of the fish by commercial and recreational fishers on neighbouring reefs 1 and 3 yr after initial capture indicates inter-reetal movements by coral trout. Direct linear distance paths are indicated $(3,7.5,11 \mathrm{~km})$. (O) Location of initial capture and release at Granite Head. 10 , ?) Best estimates of recapture locations that were obtainable from fishers

mercial fishers 3 yr later (June 1996), in a reef area approximately $11 \mathrm{~km}$ north-northwest of Lizard Island (Fig. 3).

Specimen $2(\mathrm{FL}=55.4 \mathrm{~cm}$ ) was caught for transmitter implantation in October 1994 (full moon) at the Granite Head spawning aggregation site. Within $3 \mathrm{~d}$ of release, ultrasonic tracking contact was lost with this fish. It was recaptured by recreational fishers in October 1995 in an extensive reef shoal area to the north of Lizard Island (Petricola shoais, Fig. 3). The direct, linear distance between initial capture site and the southernmost part of the shoal area is approximately $3 \mathrm{~km}$ (Fig. 3).

The third coral trout $(\mathrm{FL}=44.1 \mathrm{~cm}$ ) was initially caught at the Granite Head spawning aggregation site in October 1994 ( $1 \mathrm{~d}$ before new moon). Tracking contact was lost $8 \mathrm{~d}$ after release. This fish was recaptured in October 1995 at Eyrie Reef by a research team. The direct linear distance between site of initial capture and location of recapture is approximately $7.5 \mathrm{~km}$ (Fig. 3).

\section{Use patterns of aggregation sites}

Spawning aggregation activities of the tracked individuals showed distinct patterns of lunar activity. The number of tracked specimens present at the 4 spawn- ing sites was highest during new moon periods (Fig. 4A), with the highest participation observed in November 1994 (Fig. 4B) and in October 1995 (Fig. 4C). Underwater visual censuses at the Granite Head and North Point aggregation sites during October-November 1994 showed highest total trout counts during new moon periods in October and November. The highest count of 60 fish per $1000 \mathrm{~m}^{2}$ was observed 2 and $3 \mathrm{~d}$ before the October new moon at the Granite Head site (Fig 5A). Similar censuses conducted at all 4 spawning aggregation sites between September and December 1995 found highest densities (35 fish per $1000 \mathrm{~m}^{2}$ ) at Granite Head before the October new
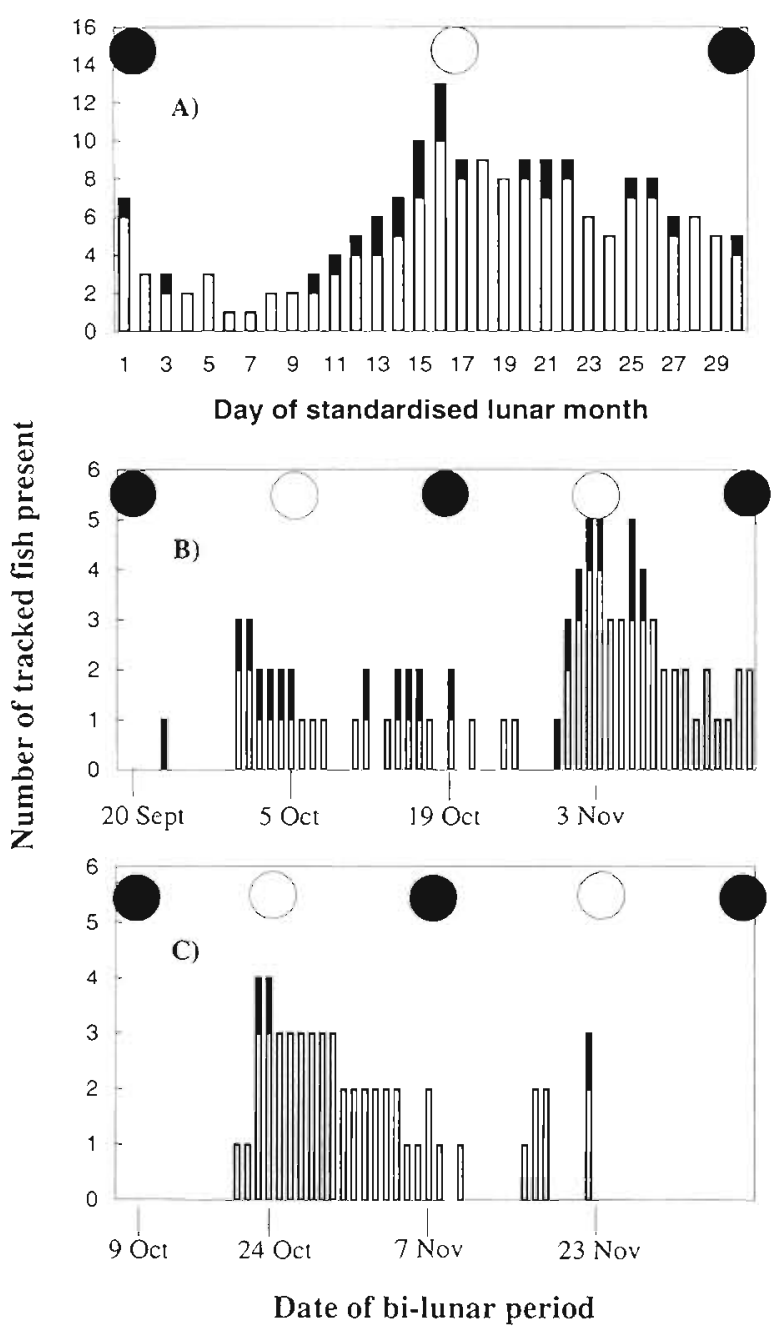

Fig. 4. Plectropomus leopardus. Number of coral trout equipped with ultrasonic transmitters present at spawning aggregation sites per day, pooled for all 4 major spawning aggregation sites. (A) Data for all tracking periods (1993 to 1995) pooled and standardised to 1 lunar cycle (full moon to full moon\}. (B) Data for 1994 tracking period, covering 2 consecutive lunar cycles. (C) Data for the 1995 tracking period, covering 2 consecutive lunar cycles. Black bars: female; white bars: male. (1) Full moon; (O) new moon 
moon (Fig $5 \mathrm{C}$ ). All 4 locations had highest densities of aggregating coral trout during this October new moon period, with a secondary peak prior to the November new moon (Fig. 5B).

Nine fish with ultrasonic transmitters were identified and observed on numerous occasions during visual censuses of the spawning aggregations. The remaining 4 were not present at aggregation sites during visual census periods. Of the 9 specimens, 6 were identified visually as male by the readily recognisable male courtship colours and behaviour. The behavioural sex determination was confirmed through gonad histology upon recovery of the tracking specimens at the end of the tracking periods. It was not possible on all occasions to identify males by their behaviour patterns during the visual census. For example, on one census day an individual was recorded as present but 'inactive'
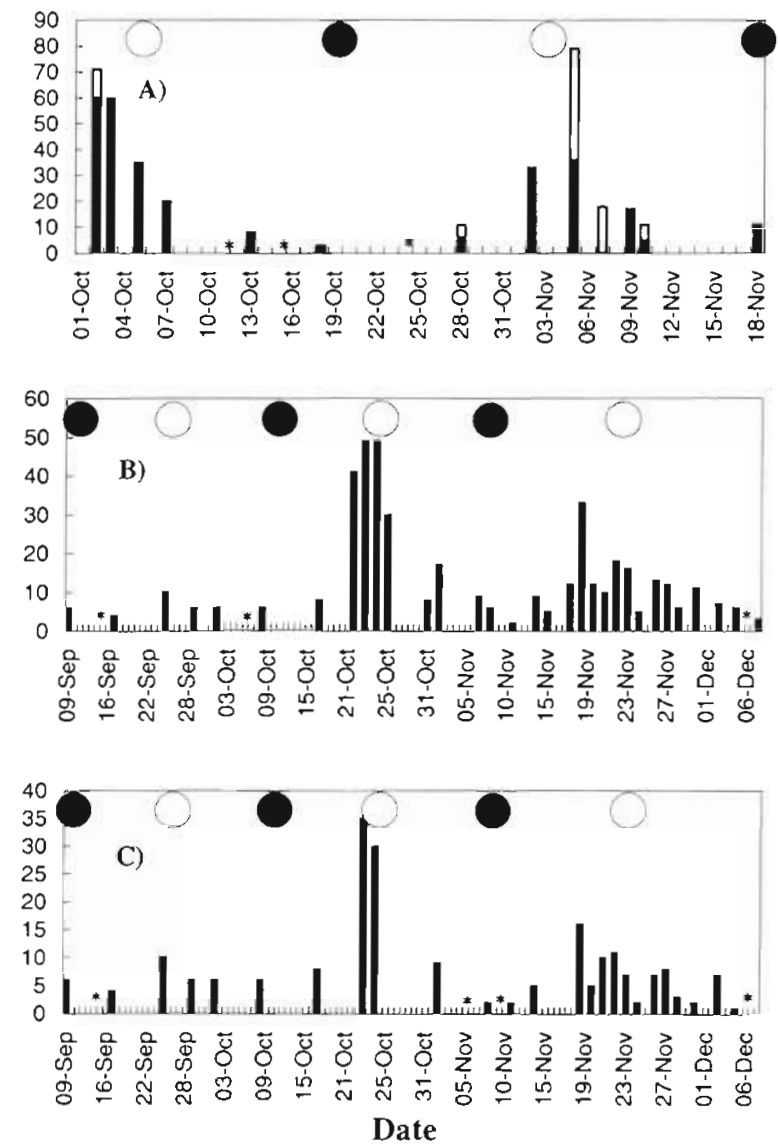

Fig. 5. Plectropomus leopardus. Underwater visual census counts of coral trout observed during the late afternoons at the spawning aggregation sites. (A) Total 1994 census counts at the 2 spawning aggregation sites known at that time. Black bars: Granite Head; white bars: North Point. (B) Total 1995 census counts at all 4 aggregation sites combined. (C) Total counts of 1995 censuses from the largest aggregation site only (Granite Head). (*) Dates of censuses with zero counts. (-) Full moon; (O) new moon

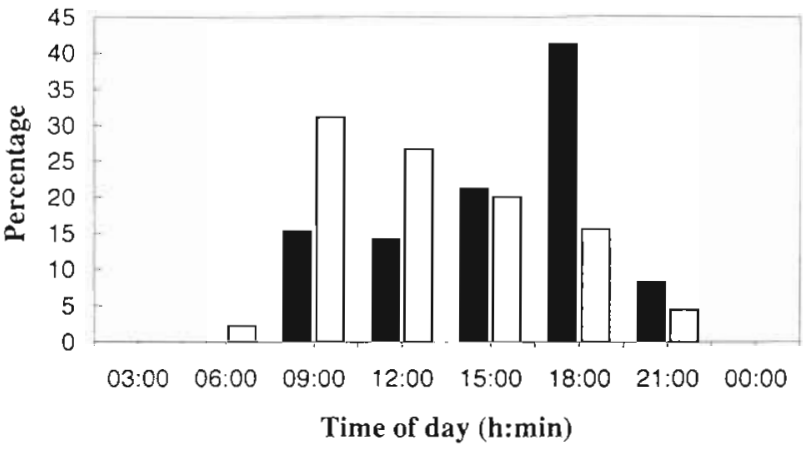

Fig. 6. Plectropomus leopardus. Percentage distribution of arrival (black bars, $\mathrm{n}=55$ observations) and cleparture (white bars, $n=45$ observations) from spawning aggregation sites for ultrasonically tracked coral trout during 1993 to 1995 , grouped into 3 -h intervals. Graph contains spawning movement occasions only if fixes included late afternoon and early morning twilight sampling

(no courtship behaviour or colours) and was not identified visually as male until a subsequent census. Thus, male tracked specimens were present 11 times during the visual censuses, but were identified correctly as males by their behaviour patterns on only 7 accasions. Hence, $36.4 \%$ of the time a known male fish was observed during the visual census, it was not identified correctly as a male.

Movements of tracked specimens to and from spawning aggregation sites occurred throughout the daytime (Fig. 6). A preference for late afternoon movements to the aggregation sites was observed, with $41.2 \%$ of all movements to the aggregation sites occurring between 16:30 and 19:30 h (Fig. 6). Time of departure from the aggregation sites was more widely spread throughout the day, with a gradual drop in departure rate discernible during the day (Fig. 6). However, $31.1 \%$ of all departures occurred between $07: 30$ and $10: 30 \mathrm{~h}$, with $60 \%$ of departures occurring during the mornings (Fig. 6). A. 2-way analysis of variance indicated that the mean time of arrival differed from the mean time of departure $\left(F_{[1,124]}=13.543, \mathrm{p}<\right.$ 0.001 ), and this pattern was the same for both sexes $\left(F_{[1,124]}=1.4856, \mathrm{p}=0.225\right)$.

Each fish utilised only 1 of the 4 sites monitored throughout the tracking periods (Fig. 2), thus displaying aggregation site fidelity. While most fish utilised that site closest to their observed home ranges, 1 male (PL 34) utilised a spawning aggregation site on a neighbouring patch reef $(740 \mathrm{~m}$ from its home range, Fig. 7A), despite the existence of a well-established aggregation site nearer to its home range $(320 \mathrm{~m}$ distance) which was used by 2 other fish from the same patch reef (PL 35 and PL 36, Fig. 7B, C). Movements to the preferred site were recorded repeatedly for this individual throughout the tracking period. 

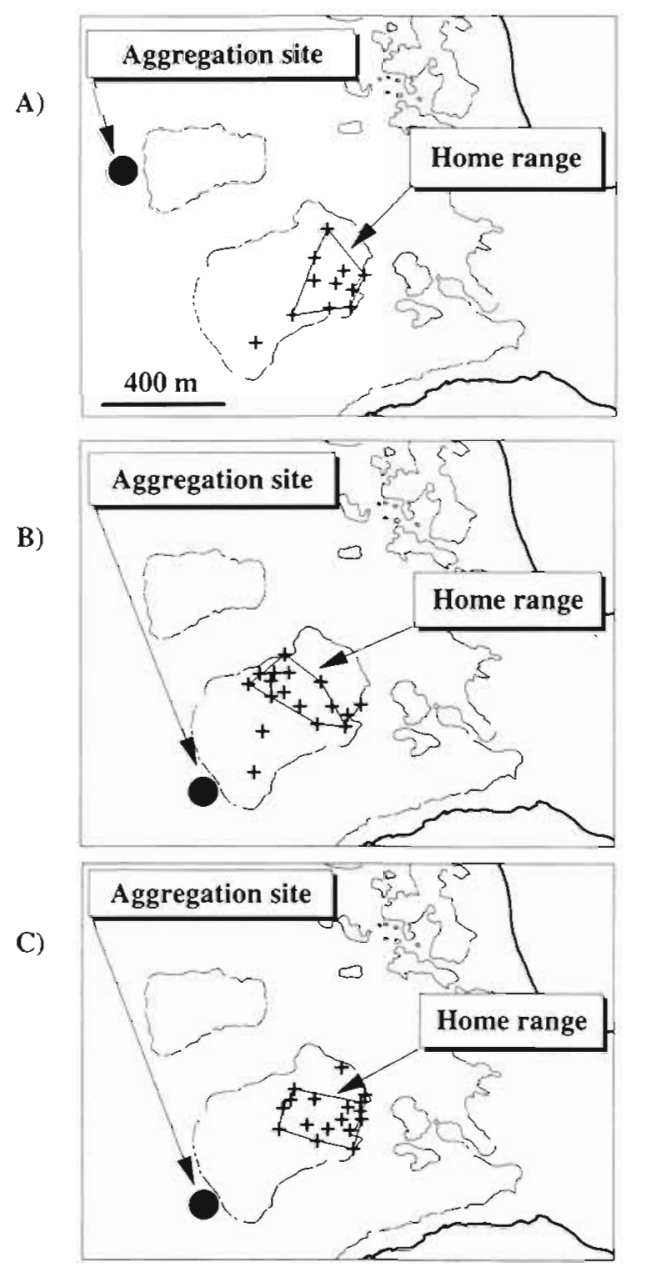

Fig. 7 Plectropomus leopardus. Maps demonstrating the unusual choice of a spawning aggregation site on a neighbouring patch reef by 1 of 3 male coral trout inhabiting the same patch reef on the backreef area on the western side of Lizard Island. (1) Spawning aggregation sites; (+) home range positions. (A) Fish PL 34 utilised a spawning aggregation site located $740 \mathrm{~m}$ away on a neighbouring patch reef, despite the existence of a well-established spawning site on the home patch reef. (B) Fish PL 35 and (C) fish PL 36 used the local spawning aggregation site (distance 280 to $320 \mathrm{~m}$ )

Aggregation residence time was calculated for each separate trip made by an individual to an aggregation site. Total residence times at the spawning aggregation sites differed between males and females $(t=$ $2.9508, \mathrm{df}=10, \mathrm{p}=0.0145$ ), with males spending, on average, 8.76 times more time at the spawning aggregation sites than females (males: mean $=316 \mathrm{~h} 33 \mathrm{~min}$ $\pm 65 \mathrm{~h} 5 \mathrm{~min}, \mathrm{n}=8$; females: mean $=36 \mathrm{~h} 4 \min \pm 17 \mathrm{~h}$ $42 \mathrm{~min}, \mathrm{n}=4$ ). No significant relationship between total residence time and size of fish (fork length) was observed for males $\left(r^{2}=0.2596, n=8, p=0.197\right)$ or females $\left(\mathrm{r}^{2}<0.0001, \mathrm{n}=4, \mathrm{p}=0.998\right)$.
Table 1. Plectropomus leopardus. Percentage distribution of day, overnight and multi-day trips to spawning aggregation sites undertaken by coral trout tracked by ultrasonic telemetry during 1993 to 1995

\begin{tabular}{|lccc|}
\hline & Day & Overnight & Multi-day \\
\hline Males & 22.7 & 43.2 & 34.1 \\
Females & 53.8 & 46.2 & 0 \\
Overall & 31.0 & 43.1 & 25.9 \\
\hline
\end{tabular}

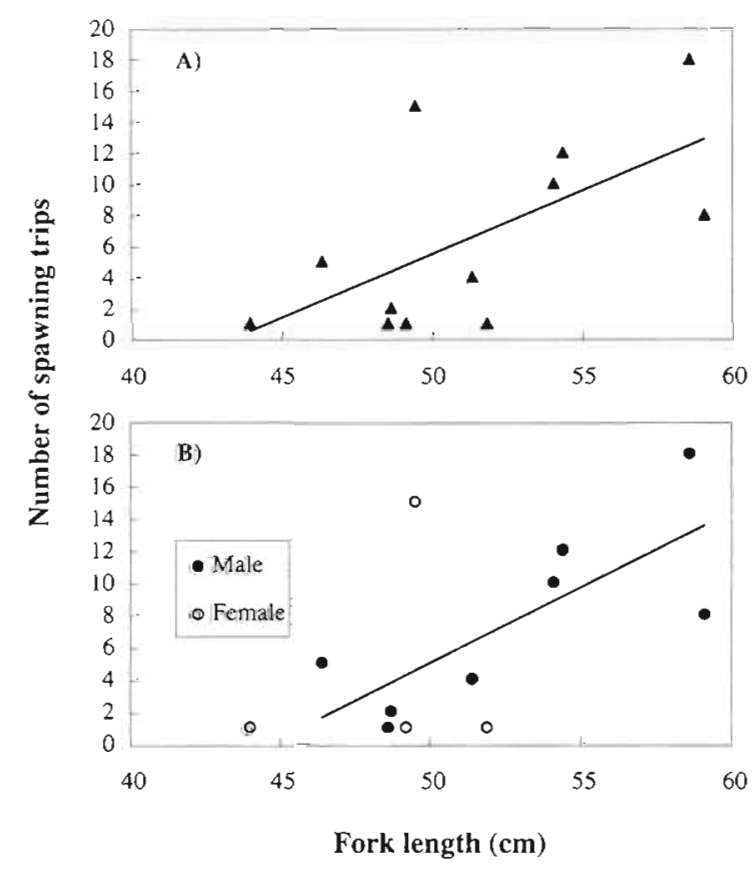

Fig. 8. Plectropomus leopardus. Relationship between number of spawning trips and size of fish (fork length) for coral trout tracked during 1993 to 1995. (A) Relationship between number of trips and body size for all coral trout, suggesting an increase in number of trips with increasing size of fish. (B) Relationship between number of trips and body size for male coral trout, suggesting an increase in number of trips with increasing body size. Female fish are superimposed for illustration purposes, but not included in regression

A breakdown of spawning trips into day-trips, overnight-trips and trips lasting several days (multiday) revealed that, for all fish combined, overnight trips contributed $43 \%$ of all occurrences, while multiday trips accounted for $26 \%$ (Table 1 ). The proportion of each trip type did differ between males and females $\left(\chi^{2}=7.73, d f=2, p=0.0209\right)$. Females undertook proportionally more day trips than male fish, and, in contrast to males, were never observed to make multiday spawning excursions (Table 1).

Male Plectropomus leopardus were more likely to make several trips to spawning aggregation sites dur- 
ing the time periods monitored than female trout $\left(\chi^{2}=\right.$ 4.91, $\mathrm{df}=1, \mathrm{p}=0.027 \mathrm{f}$. Of the 4 females, 3 undertook only a single excursion (median $=1$, range $=1,1,1,15$; Fig 8B), while 7 out of 8 males moved to the spawning aggregation sites on more than one occasion (median = 7 , range $=1,2,4,5,8,10,12,18$ : Fig. $8 \mathrm{~B}$ ). The present results suggest that larger fish undertake more trips to spawning aggregation sites than do smaller fish $\left(\mathrm{r}^{2}=\right.$ 0.3887, $p=0.0303$; Fig. 8A), a pattern that is more distinct for male $P$. leopardus $\left(\mathrm{r}^{2}=0.5978, \mathrm{p}=0.0244\right.$, Fig. 8B).

\section{DISCUSSION}

The present study is the first to locate spawning aggregations of Plectropomus leopardus by using ultrasonic telemetry on a reef which had no previously published reports of aggregation sites. There were 4 spawning aggregation sites of $P$. leopardus detected based on the monitoring of $12 \mathrm{~km}$ of island coastline, which represents approximately $2 / 3$ of the total coastline of the island (not including the lagoon area). The existence and regular use of several aggregation sites indicates that multiple spawning aggregation sites per reef exist for $P$. leopardus on the Great Barrier Reef. Samoilys (1997), using visual searches on Scuba, also reported several aggregation sites on 2 mid-shelf reefs of the GBR.

The spawning movements observed in the present study represent the first records of 2-way movements of a large coral reef fish between home locations and spawning sites. After participation at aggregation events, fish did return to the original home ranges from which they had moved (Zeller 1997a, b). That 3 of the specimens initially caught and released at the spawning aggregation site Granite Head in 1993/94 were recaptured in reefal habitats 3 to $11 \mathrm{~km}$ from the Lizard Island spawning aggregation site suggests that movements of Plectropomus leopardus between reefs do occur. The possibility that tagging may have influenced the behaviour of these specimens cannot be excluded. However, other tracked specimens all remained at their capture location to re-establish home ranges (Zeller 1997a, b). The nature of the inter-reefal habitat around Lizard Island is not well known. However, several hard-bottom habitats, in addition to substantial sand and seagrass areas, are known to exist in these inter-reefal areas ( $\mathrm{L}$. Vale pers. comm.). Charted water depths around Lizard Island range from 25 to $46 \mathrm{~m}$ (Australian Hydrographic Office, Chart AUS 832). Movements up to $10 \mathrm{~km}$ between patch reef complexes isolated from the original tagging reef, and associated with spawning aggregations, have also been reported for Epinephelus polyphekadion in Palau
(Johannes et al. 1995). Several 1 -way movements from spawning aggregations have been recorded from tagged individuals in investigations of Caribbean serranids. The distances recorded ranged from $13 \mathrm{~km}$ for Epinephelus guttatus (Burnett-Herkes 1975 in Shapiro 1987) to $29-72 \mathrm{~km}$ for Epinephelus morio (Moe 1969) to $110 \mathrm{~km}$ (Colin 1992) and even $240 \mathrm{~km}$ for Epinephelus striatus (Carter et al. 1994 in Sadovy 1994). Future tracking studies should consider the possibility of $P$. leopardus moving offshore into inter-reefal habitats.

\section{Use patterns of aggregation sites}

Only $31 \%$ of all tracked individuals took part in aggregation events. This low rate of participation at spawning aggregation sites by tracked specimens could be due to either localised spawning efforts, stress or individual variation.

It is possible that not all reproductive activity occurs at major aggregation sites. Localised spawning may account for the lack of movement by some of the tracked specimens to the major aggregation sites detected. This suggestion is supported by the discovery of 3 smaller courtship locations around Lizard Island during visual census surveys in 1995 (A, B and C, Fig. 1). Similar minor aggregation and courtship sites of Plectropomus leopardus have been reported by Samoilys (1997). Whether most reproductive effort occurs exclusively at large aggregation sites is of critical importance in devising suitable management strategies (Sadovy 1994).

Stress associated with capture, handling or transmitter attachment may lead a fish to delay its reproductive effort for some time, or even inhibit reproduction for the season (Pankhurst \& Van Der Kraak 1997). However, histological examination of the gonads of tracked specimens which had not moved to an aggregation site indicated that all were reproductively active. This observation suggests they had spawned during the current reproductive season (S. Adams pers. comm.).

However, there may also be individual variation in the seasonal timing of reproductive effort. Some of the tracked specimens captured for transmitter implantation might have either participated in spawning aggregation events very early in the season (i.e. prior to initial capture), or were preparing to spawn late in the year, i.e. after the tracking period terminated.

The movements to spawning sites during the springearly summer periods recorded through ultrasonic tracking in this study corresponded with the build up of aggregations recorded in the visual censuses. No movements to aggregation sites or movements significantly outside of established home ranges were ever recorded during tracking periods outside the reported 
spawning season (Zeller $1997 \mathrm{a}$, b). Furthermore, during visual assessments of the spawning aggregation sites at North Point and Granite Head during February-March 1994 and 1995, and May 1995 no evidence of courtship or aggregating behaviour was seen.

The data support the reported build up of aggregations of Plectropomus leopardus and other Indo-Pacific serranids in relation to the lunar cycle, with peak abundances over the new moon periods (Johannes 1988, Johannes et al. 1994, 1995, Samoilys \& Squire 1994). This contrasts with studies on some Caribbean serranids (e.g. Epinephelus striatus, E. guttatus) which report peak aggregations over the full moon periods (Colin 1992, Shapiro et al. 1993)

Interestingly, while attendance at spawning aggregation sites was highest over new moon periods, many tracked fish remained at, or returned to, the aggregation sites over the full moon period. This pattern was especially evident for male Plectropomus leopardus. In Palau, several individual $P$. areolatus tagged by Johannes et al. (1995) at the spawning aggregation sites were resighted during subsequent months. Similarly, all individuals resighted in their study were male (based on size and colouration). Repeated presence at aggregation sites of $P$. leopardus was also suggested by Samoilys \& Roelofs (1996). However, visual census monitoring was not undertaken daily in their study, therefore short-term visits by tagged fish might have been missed. Such short-term visits (i.e. day or overnight trips) accounted for $74 \%$ of all recorded movements to the monitored aggregation sites in the present study.

The observed timing of movements to the spawning aggregation sites in this study, with $41 \%$ of movements in the late afternoon, supports the observation by Samoilys (1997) of numbers increasing at aggregation sites during the day. Johannes et al. (1994) also reported numbers of Epinephelus fuscoguttatus and E. polyphekadion nearly doubling in the late afternoon of the day before the new moon.

The pattern of predominantly late arrival at and early departure from aggregation sites indicates that Plectropomus leopardus moves from home ranges to spawning sites during daytime. This observation is supported by the fact that none of the tracked specimens took more than one daytime period to move between the home range and the spawning aggregation site. Johannes (1988) recorded $P$. areolatus in the Solomon Islands leaving aggregation sites around 07:00 h on the day after the new moon, with the complete aggregation $(300+$ fish) having departed by $07: 20 \mathrm{~h}$.

The pattern of arrival and departure recorded in the present study illustrates that the narrow time window of actual spawning rushes observed during the dusk period is of primary importance and appears to represent the major spawning time (Colin 1992, Samoilys 1997). Based on the present observations, the possibility of nocturnal or dawn spawning cannot be excluded. However, no evidence of nocturnal or dawn spawning has been recorded for serranids (Sadovy 1996, Samoilys 1997).

Some clear differences in the residence patterns at aggregations were observed between male and female Plectropomus leopardus. Males spent considerably longer at spawning sites than females, and also undertook more trips to spawning aggregation sites. The evidence of longer stays for males is consistent with histological information suggesting continuous spawning activity by males over several days (Ferreira 1995). Sex-dependent patterns of presence on spawning grounds have also been reported for other fishes, such as the temperate water North-Atlantic cod Gadus morhua (Morgan \& Trippel 1996).

The absence of any observed multi-day stays at aggregation sites by female coral trout might indicate that females do not undergo repetitive daily spawning events, although repeated spawning rushes by the same female on any single day do occur (Samoilys \& Squire 1994). This potential absence of repeated daily spawning is supported by the observations that hormone induced ovulation of female serranids produced viable eggs only in the first of up to 3 consecutive nights (Tucker 1994, Tucker \& Fitzgerald 1994). However, histological evidence indicates that female Plectropomus leopardus are multiple or batch spawners (Ferreira 1995). Unfortunately, the limited number of female $P$. leopardus tracked to spawning aggregation events in the present study makes any generalised conclusions regarding the timing of repeated, multiple spawning by females difficult. Future studies clearly need to address this shortfall by targeting individuals selectively, either through developing non-destructive sexing techniques for specimen selection, or by preferentially targeting smaller individuals for tracking.

\section{Use of aggregations for stock assessment}

Spawning aggregations of serranids represent a unique opportunity for stock assessments and monitoring of relative changes in abundance of otherwise widely distributed and sparsely scattered populations (Shapiro et al. 1993). However, as identified in the present study, in order to utilise aggregations of Plectropomus leopardus for stock assessment purposes, the following points need to be considered:

(1) Only $31 \%$ of the monitored population of coral trout equipped with transmitters were found to participate in spawning aggregation events. Such a low rate 
of participation suggests either that not all reproductive activity of Plectropomus leopardus occurs at major aggregation sites, or that considerable individual variation in timing of reproduction exists during the spawning season. This uncertainty may greatly influence any stock assessment undertaken at aggregation sites only. The results suggest that assessments need to consider the participation rate at aggregation events and assess the potential for substantial year to year variation in this participation rate. The alternative possibility that not all individuals spawn every year is not supported by the existing histological evidence (Ferreira 1995).

(2) The present study suggested sex-specific turnover rates at aggregations. Most females only undertook 1 trip over the approximate 2 mo tracking periods during which they stayed for an average of only $36 \mathrm{~h}$. Thus there would be higher turnover rates for female than for male fish over the lunar lifespan of an aggregation. Therefore, a single visual census would greatly underestimate the female stock component. Alternatively, 2 repeated censuses on 2 separate days will have a high likelihood of counting different female but the same male individuals.

(3) This study demonstrated the problem of sex identification during censuses at aggregations. Given the observed differences in usage patterns by the sexes, it is important to be able to estimate the sex ratio of fishes recorded at aggregation sites. Based on the visual recording of tracked specimens, it became apparent that $36 \%$ of the times a known male Plectropomus leopardus was seen at an aggregation site, it was not identified as a male based on observable courtship colours and behaviour. The fact that a proportion of the male population cannot be sexed during visual censuses will have to be taken into account in relation to turnover rates and stock estimates using aggregation site censuses.

\section{Conclusions and implications}

The documentation by ultrasonic telemetry of aspects of the dynamics of spawning aggregations of Plectropomus leopardus has distinct implications for the management of this fishery. The reliance of $P$. leopardus on several aggregation sites per reef, and the low rate of participation at these major aggregation sites coupled with the potential for secondary, localised spawning events, supports the notion of greater resilience of $P$. leopardus stocks to fishing pressures on aggregations compared to some other serranid species. However, the strong site fidelity observed for all individuals may make individual aggregations vulnerable to depletion. The available evidence suggests that $P$. leopardus are dependent primarily on aggregation sites on their home reef for reproductive activities. Thus, sustainable management of at least some of the aggregation sites on each reef through spatial or temporal closures might be appropriate for the long-term maintenance of local populations.

Assuming similar vulnerability to the fishing gear for each sex, the longer residence times of males at aggregation sites makes them more vulnerable to aggregation fishing. Furthermore, sex dependent turnover rates, coupled with the problem of visual identification of sex, complicates the use of aggregation events for stock assessment purposes. However, further quantification of these factors may permit a more informative approach to stock assessment.

Acknowledgements. Dr G. Russ, Dr N. Moltschaniwskyj, Ms M. Samoilys, Ms S. Adams, and anonymous reviewers provided valuable criticisms of the manuscript. This research was funded by the Lizard Island Reef Research Foundation and the Australian Research Council. Logistic support was provided by the Department of Marine Biology, James Cook University of North Queensland. This paper is a contribution from the Lizard Island Research Station, a facility of the Australian Museum.

\section{LITERATURE CITED}

Colin PL (1992) Reproduction of the Nassau groper, Epinephelus striatus (Pisces:Serranidae) and its relationship to environmental conditions. Environ Biol Fishes 34:357-377

Colin PL, Clavijo IE (1988) Spawning activity of fishes producing pelagic eggs on a shelf edge coral reef, southwestern Puerto Rico. Bull Mar Sci 43(2):249-279

Colin PL, Shapiro DY, Weiler D (1987) Aspects of the reproduction of two groupers, Epinephelus guttatus and $E$ striatus in the West Indies. Bull Mar Sci 40(2):220-230

Davis TLO, West GJ (1993) Maturation, reproductive seasonality, fecundity, and spawning frequency in Lujanus vittus (Quoy and Gaimard) from the north west Shelf of Australia. Fish Bull 91:224-236

Ebisawa A (1990) Reproductive biology of Lethrinus nebulosus (Pisces: Lethrinidae) around the Okinawa waters Nippon Suisan Gakkai 56:1941-1954

Ferreira BP (1995) Reproduction of the common coral trout Plectropomus leopardus (Serranidae: Epinephelinae) from the central and northern Great Barrier Reef, Australia. Bull Mar Sci 56(2):653-669

Hart LG, Summerfelt RC (1975) Surgical procedures for implanting ultrasonic transmitters into flathead catfish (Pylodictis olivaris). Trans Am Fish Soc 104:56-59

Higgs JB (1996) A review of published fisheries dependent and independent surveys of recreational Great Barrier Reef line fisheries and demersal reef fish stocks. Report prepared for the Queensland Fisheries Management Authority, Brisbane

Holland KN, Brill R, Ferguson S, Chang R, Yost R (1985) A small vessel technique for tracking pelagic fish. Mar Fish Rev 47(4):26-32

Holland KN, Peterson JD, Lowe CG, Wetherbee BM (1993) Movements, distribution and growth rates of the white 
goatfish Mulloides flavolineatus in a fisheries conservation zone. Bull Mar Sci 52(3):982-992

Johannes RE (1981) Words of the lagoon: fishing and marine lore in the Palau District of Micronesia, 1st edn. University of California Press, Berkeley

Johannes RE (1988) Spawning aggregation of the grouper, Plectropomus areolatus (Ruppel) in the Solomon Islands. Proc 6th Int Coral Reef Symp, Townsville, Australia. 2: $751-755$

Johannes RE, Squire L (1988) Aggregations of coral trout and Maori wrasse in the Great Barrier Reef Marine Park. Report to GBRMPA, Townsville

Johannes RE, Squire L, Graham T (1994) Developing a proto$\mathrm{col}$ for monitoring spawning aggregations of Palauan serranids to facilitate the formulation and evaluation of strategies for their management. Progress report, South Pacific Forum Fisheries Agency, Honiara

Johannes RE, Squire L, Graham T, Renguul H, Bukurrou A (1995) Palau grouper spawning aggregation research project. 1995 Progress Report, South Pacific Forum Fisheries Agency, Honiara

Kailola PJ, Williams MJ, Stewart PC, Reichelt RE, McNee A, Grieve C (1993) Australian fisheries resources. Bureau of Resource Sciences, Department of Primary Industries and Energy, and Fisheries Research and Development Corporation, Canberra

Matthews KR, Quinn TP, Miller BS (1990) Use of ultrasonic transmitters to track demersal rockfish movements on shallow rocky reefs. Am Fish Soc Symp 7:375-379

Mazeroll AI, Montgomery WL (1995) Structure and organization of local migrations in brown surgeonfish (Acanthurus nigrofuscus\}. Ethology 99:89-106

Moe MA (1969) Biology of the red grouper Epinephelus morio (Valenciennes) from the eastern Gulf of Mexico. Prof Papers Series 10, Florida Dept of Natural Resources, Marine Research Laboratory, St. Petersburg

Morgan MJ, Trippel EA (1996) Skewed sex ratios in spawning shoals of Atlantic cod (Gadus morhua). ICES J Mar Sci 53: 820-826

Mortensen DG (1990) Use of staple sutures to close surgical incisions for transmitter implants. Am Fish Soc Symp 7: $380-383$

Myrberg AA, Montgomery WL, Fishelson L (1988) The reproductive behaviour of Acanthurus nigrofuscus (Forskal) and other surgeonfishes (Fam. Acanthuridae) off Eilat, Israel (Gulf of Aqaba, Red Sea). Ethology 79:31-61

Pankhurst NW, Van Der Kraak G (1997) Effects of stress on reproduction and growth of fish. In: Iwama G (ed) Fish stress and health in aquaculture, 1 st edn. Cambridge University Press, Cambridge, p 73-93

Robertson DR (1983) On the spawning behavior and spawning cycles of eight surgeonfishes (Acanthuridae) from the Indio-Pacific. Environ Biol Fishes 9:193-223

Sadovy Y (1994) Grouper stocks of the western central Atlantic: the need for management and management needs. Proc Gulf Carib Fish Inst 43:43-64

Sadovy Y (1996) Reproduction of reef fisheries species. In: Polunin NVC, Roberts CM (eds) Reef fisheries. Chapman and Hall, London, p 15-60

Editorial responsibility: Otto Kinne (Editor), Oldendorf/Luhe, Germany
Sadovy Y, Domeier ML (1994) Aggregation and spawning in the tiger grouper, Mycteroperca tigris (Pisces: Serranidae). Copeia 1994(2):511-516

Sadovy Y, Rosario A, Roman A (1994) Reproduction in an aggregating grouper, the red Hind, Epinephelus guttatus. Environ Biol Fishes 41:269-286

Samoilys MA (1997) Periodicity of spawning aggregations of coral trout Plectropomus leopardus (Pisces: Serranidae) on the northern Great Barrier Reef. Mar Ecol Prog Ser 160: $149-159$

Samoilys MA, Roelofs A (1996) Reproductive strategies of the common coral trout on the northern Great Barrier Reef. Cooperative Research Centre Reef Research Tech Rep Task 2.4.2 Rep 1, Townsville

Samoilys MA, Squire L (1994) Preliminary observations on the spawning behavior of coral trout, Plectropomus leopardus (Pisces: Serranidae), on the Great Barrier Reef. Bull Mar Sci 54(1):332-342

Shapiro DY (1987) Reproduction in groupers. In: Polovina JJ, Ralston S (eds) Tropical snappers and groupers. Biology and fisheries management. Westview Press, Boulder

Shapiro DY, Sadovy Y, McGehee MA (1993) Size, composition, and spatial structure of the annual spawning aggregations of the Red Hind, Epinephelus guttatus (Pisces: Serranidae). Copeia 1993(2):399-406

Sokal RR, Rohlf FJ (1981) Biometry. The principles and practice of statistics in biological research, 2nd edn. Freeman \& Company, New York

Thresher RE (1984) Reproduction in reef fishes, 1st edn. TFH Publications, Neptune City, NJ

Todd IA (1993) Wildtrack. Non-parametric home range analysis for the Macintosh. Version 1.11 User's guide. Dept of Zoology, University of Oxford

Tucker JW (1994) Spawning by captive serranid fishes: a review. J World Aquacult Soc 25(3):345-359

Tucker JW, Fitzgerald WJ (1994) Induced spawning of two western tropical pacific groupers, Plectropomus areolatus and Epinehelus fuscoguttatus, in Palau. Asian Fish Sci $7(1): 57-62$

Underwood AJ (1981) Techniques of analysis of variance in experimental marine biology and ecology. Oceanogr Mar Biol Annu Rev 19:513-605

Warner RR (1995) Large mating aggregations and daily longdistance spawning migrations in the bluehead wrasse, Thalassoma bifasciatum. Environ Biol Fishes 44:337-345

White GC, Garrott RA (1990) Analysis of wildlife radio-tracking data, 1st edn. Academic Press, San Diego

Williams D McB, Russ GR (1994) Review of data on fishes of commercial and recreational fishing interest on the Great Barrier Reef. Great Barrier Reef Marine Park Authority Research Publication No. 33, Townsville

Zeller DC (1997a) Patterns of movement of Plectropomus leopardus (Serranidae) in relation to spawning aggregations and marine protected areas, as determined by ultrasonic telemetry. PhD thesis, James Cook University, Townsville

Zeller DC (1997b) Home range and activity patterns of the coral trout Plectropomus leopardus (Serranidae). Mar Ecol Prog Ser 154:65-77

Submitted: June 27, 1997; Accepted: December 1, 1997

Proofs received from author(s): January 26, 1998 